\title{
Conserved Cytogenetic Features in the Amazonian Arapaima, Arapaima gigas (Schinz 1822) from Jamari River, Rondônia-Brazil
}

\author{
Renata da Rosa ${ }^{1}$, Marceléia Rubert ${ }^{2}$, Mauro Caetano-Filho ${ }^{3}$ and Lucia Giuliano-Caetano ${ }^{*}, 4$ \\ ${ }^{1}$ Departamento de Biologia Celular e Genética, Universidade Estadual de Maringá, CEP 87020-900, Caixa Postal 331, \\ Maringá, Paraná, Brazil \\ ${ }^{2}$ Departamento de Genética e Evolução, Universidade Federal de São Carlos, CEP 13565-905, Caixa Postal 676, São \\ Carlos, São Paulo, Brazil \\ ${ }^{3}$ Departamento de Biologia Animal e Vegetal, CCB, Universidade Estadual de Londrina. CEP 86051-990, Caixa Postal \\ 6001, Londrina, Paraná, Brazil
}

${ }^{4}$ Departamento de Biologia Geral, CCB, Universidade Estadual de Londrina. CEP 86051-990, Caixa Postal 6001, Londrina, Paraná, Brazil

\begin{abstract}
Specimens of Arapaima gigas from Jamari River (RO) were cytogenetically analyzed. A diploid number of $2 \mathrm{n}=56$ chromosomes was found $(28 \mathrm{~m}-\mathrm{sm}+28 \mathrm{st}-\mathrm{a})$. Secondary constrictions were observed on the short arms of chromosome 3. Nucleolar Organizer Regions (NORs) were detected at the subterminal region on short arms of the third chromosomal pair by both silver nitrate staining and FISH with $45 \mathrm{~S}$ rDNA probe, being equivalent to secondary constrictions. The ribosomal sites were also characterized by size heteromorphism and presence of $\mathrm{CMA}_{3}{ }^{+} / \mathrm{DAPI}^{-}$blocks. The constitutive heterochromatin was located at pericentromeric region of some chromosomes. After sequential Cbanding and base-specific fluorochromes staining, most of the heterochromatins proved to be neutral, i.e., with similar amounts of AT and GC bases. Nonetheless, some heterochromatic regions were marked by GC-specific fluorochromes in one chromosomal pair and by AT-specific fluorochrome staining on two pairs. The present data are in agreement with previous reports in populations from Araguaya River, indicating that conserved cytogenetic features are present in this important fish species.
\end{abstract}

Keywords: Fish cytogenetics, pirarucu, chromosomal conservativeness, FISH.

\section{INTRODUCTION}

The order Osteoglossiformes comprises of four families, 28 genera, and nearly 218 heavy-bodied tropical fish species widespread at different regions in Africa, Asia, Oceania, and South America [1]. The family Arapaimidae is composed of two species, Heterotis niloticus from Africa, and Arapaima gigas from the Neotropical region [2]. These fishes present some primitive features, displaying a bony tongue and a body shape ranging from cylindrical at the anterior portion to laterally compress at the posterior portion [3].

The Amazonian arapaima, Arapaima gigas (Schinz 1822), locally known as "pirarucu" in Brazil, is found throughout the Amazon basin. Fossil evidence indicates that a similar species was formerly found in Colombia's Magdalena River basin as well and suggests that the Arapaima lineage originated before the Cretaceous AfroSouth American drift/vicariance event [4]. A. gigas is a carnivore species and one of the largest freshwater fishes in the

*Address correspondence to this author at the Departamento de Biologia Geral - CCB - Universidade Estadual de Londrina, P. O. Box 6001 - CEP: 86051-990, Londrina - Paraná - Brazil; Tel: 55 (43)33714417; Fax: 55 (43)33714527; E-mail: giuliano@uel.br world, able to reach up to $390 \mathrm{~cm}$ in length. It presents a territorialist behaviour, inhabiting lakes and performing short-range migrations. Another remarkable feature of this species is the presence of a mandatory aerial respiratory system $[2,3]$.

Despite the large number of studies on conservation and management [5-7], cytogenetic data are scarce in A. gigas. Marques et al. [8] carried out cytogenetic studies in a population of this species collected in Middle Araguaya River, municipality of Araguaiana (MT, Brazil). These authors reported a diploid number of $2 n=56$ chromosomes for both males and females, single NORs, and small heterochromatic blocks at the centromeric region.

Therefore, the goal of the present work is to analyze, cytogenetically, specimens of Arapaima gigas from Jamari River, Amazonian basin - Ariquemes city - RO, in order to increase the information about number, organization, and structure of chromosomes in this species.

\section{MATERIAL AND METHODS}

Four specimens of Arapaima gigas were collected in the Jamari River, Ariquemes city, Rondônia, Brazil, and trans- 


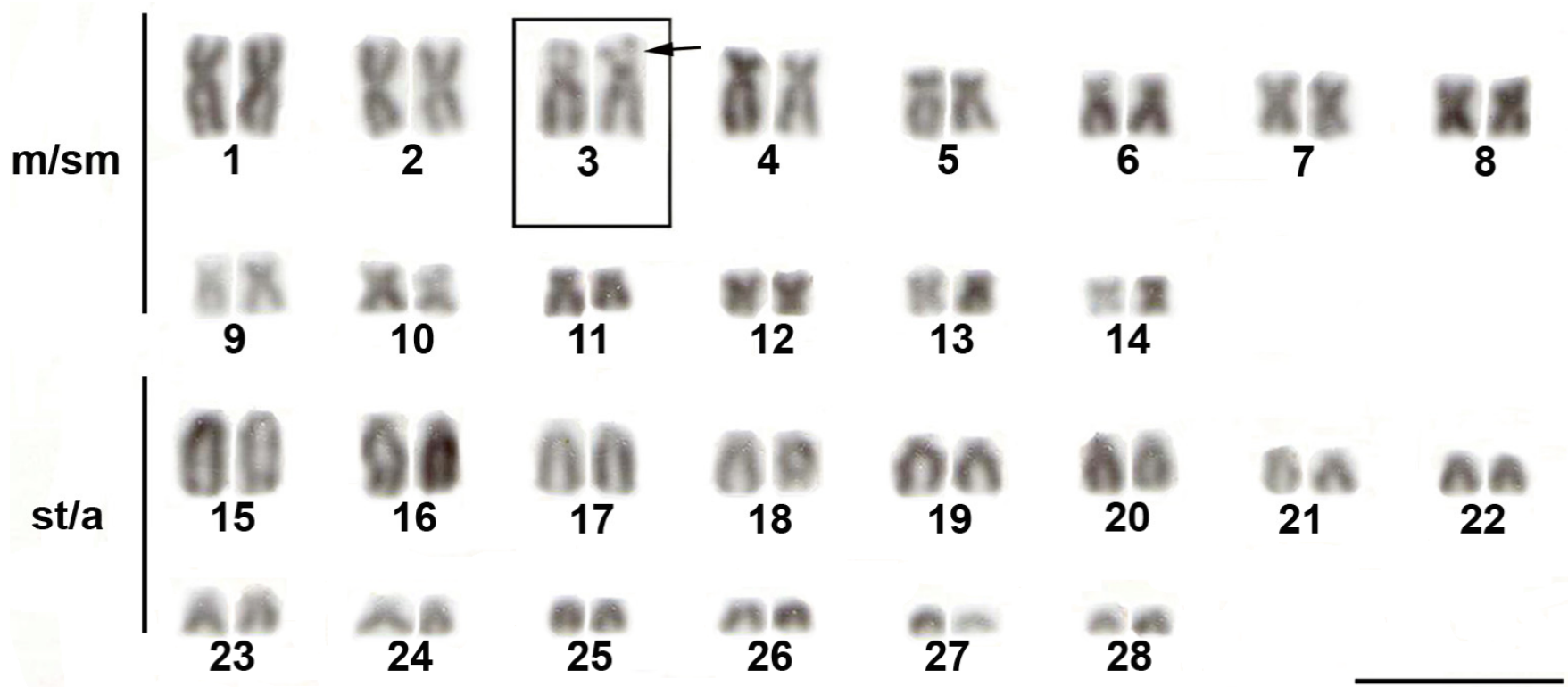

Fig. (1). Karyotype of Arapaima gigas from Jamari River. The secondary constriction (arrow) is evident on pair 3 (in square). Bar $=5 \mu$ m.

ported to tanks in the Fish Culture Facility at Universidade Estadual de Londrina.

Mitotic metaphases were obtained through lymphocyte culture using blood samples from the caudal vein [9]. We analyzed one hundred metaphases per specimen. The chromosomes were measured using the computer applicative MicroMeasure version 3.3 [10] and classified as metacentric (m), submetacentric (sm), subtelocentric (st) and acrocentric (a) according to the arm ratio [11] with slight modifications. Subtelocentric (st), and acrocentric (a) chromosomes were grouped in the same category (st-a). To calculate the fundamental number $(\mathrm{FN})$, both $\mathbf{m}$ and $\mathbf{s m}$ chromosomes were regarded as bi-armed elements, while st-a chromosomes were supposed to bear one arm. Nucleolar Organizer Regions (NORs) were detected by silver nitrate staining (AgNOR) [12] and fluorescent in situ hybridization (FISH), performed according to Heslop-Harrison et al. [13] and Cuadrado and Jouve [14], respectively, using a 45S rDNA probe ( $\mathrm{pTa} 71)$ obtained from Triticum aestivum [15]. The GC- and AT-rich segments were identified by fluorochrome staining with Chromomycin $\mathrm{A}_{3}$ and DAPI, respectively [16]. The pattern of heterochromatin distribution was detected by C-banding [17]. The chemical nature of C-bands was determined by DAPI and $\mathrm{CMA}_{3}$ staining after the $\mathrm{C}$-banding procedure.

\section{RESULTS}

All specimens presented a diploid number of $2 n=56$. The karyotype was composed of $28 \mathrm{~m}$-sm+28st-a chromosomes $(\mathrm{FN}=84)$. The third chromosomal pair presented secondary constrictions on short arms (Fig. 1).

Ag-NORs were detected at the subterminal region on short arms of the pair 3, equivalent to the secondary constrictions. Two individuals presented both homologous from such pair 3 bearing subterminal NORs, sometimes displaying a discrete size heteromorphism (Fig. 2a), while the others presented silver nitrate marks on just a single chromosome from the third pair (Fig. 2b).

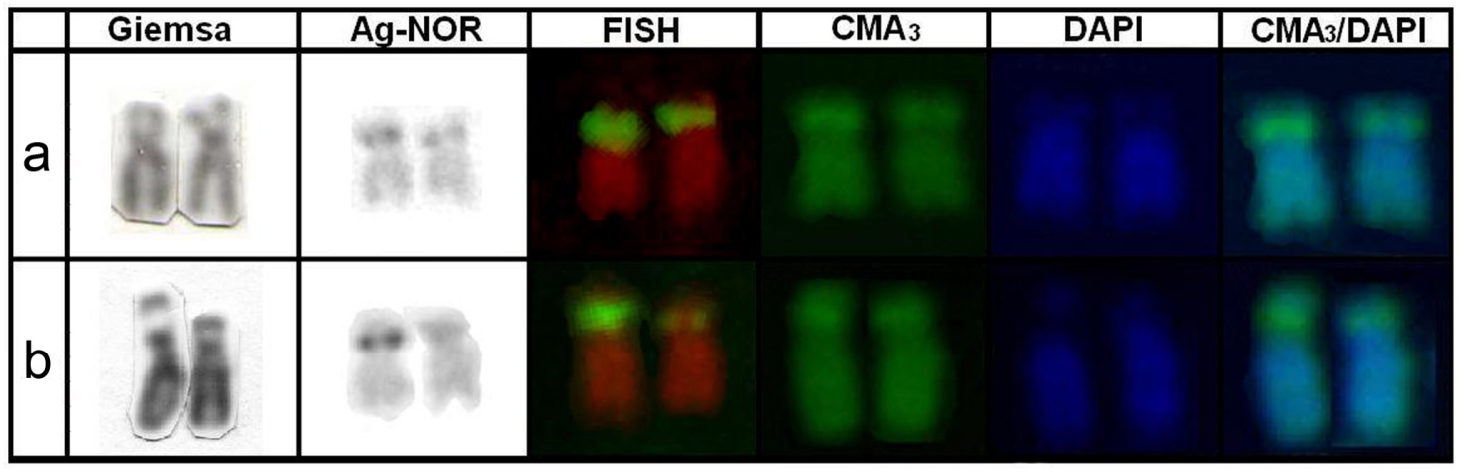

Fig. (2). Comparison of the pair 3 in distinct specimens of Arapaima gigas: a) secondary constrictions on both chromosomes; b) presence of heteromorphism of ribosomal sites (secondary constriction in one homologous). The ribosomal sites are evidenced by staining with: Giemsa, silver nitrate (Ag-NOR), fluorescent in situ hybridization (FISH), Chromomycin $\mathrm{A}_{3}\left(\mathrm{CMA}_{3}\right)$, DAPI and overlapping of CMA ${ }_{3}$ and DAPI fluorochromes $\left(\mathrm{CMA}_{3} / \mathrm{DAPI}\right)$. 
The NOR-bearing chromosomes were intensively stained by $\mathrm{CMA}_{3}$ and negatively marked by DAPI at major rDNA sites. When both images were overlapped, it was possible to confirm that these regions were equivalent to NORs, revealing a typical GC-rich composition (Fig. 2).

The C-banding revealed small amounts of heterochromatin on many chromosomes, mainly at pericentromeric regions (Fig. 3a). No heterochromatic blocks associated with NORs were detected (Fig. 3a). Besides conventional Cbanding staining, the heterochromatic regions were sequentially stained by both $\mathrm{CMA}_{3}$ and DAPI. A neutral distribution of bases, i.e., similar amounts of AT and GC bases was observed in three chromosomes. One chromosomal pair showed GC-rich heterochromatin and two other pairs were marked by AT-specific fluorochromes staining (Fig. 3b and c).

\section{DISCUSSION}

Because of its great commercial importance and overexploitation, populations of Arapaima gigas have been depleted and this species has become extinct in some Amazonian areas [18]. The present results showed similar karyotype features with previous reports in A. gigas. A diploid number of 56 chromosomes were also reported in specimens from Araguaya River, Amazon region, by Marques et al. [8].

In the specimens of $A$. gigas from Rondônia, the subterminal secondary constrictions were located on the third chromosomal pair, coincidently to the active single NORs, just like reported in the populations from Araguaya River $[19,8]$. Indeed, most of the Neotropical fish species present single NORs, such as reported in Curimatidae [20], Parodontidae [21, 22], Salminae, and Bryconinae [23], among others.

Besides carrying single NORs, both Araguaya and Rondônia populations presented a size heteromorphism in ribosomal sites, as revealed by the number of detectable secondary constrictions. In the present work, two specimens carried secondary constrictions and active NORs on both homologous, while the others presented marks on a single chromosome after silver nitrate staining (Fig. 2).
The NOR size heteromorphism was more evident after FISH, since a conspicuous block was observed in one chromosome, probably the same was observed by silver nitrate staining, while its homologous bearing a smaller segment remained undetected or unexpressed. Such heteromorphism is likely to be related to unequal crossovers (Fig. 2b).

The GC-rich blocks, as revealed by $\mathrm{CMA}_{3}$ staining, were located at subterminal position on chromosomes from the pair 3, equivalent to NORs. This result is the first report about the application of fluorochromes in A. gigas. As expected, the application of AT-specific fluorochromes showed that NORs are negatively stained, i.e., they present few amounts of AT bases. When both images were overlapped, it was possible to highlight the GC-rich regions, while the rest of chromosomal arms remained neutral, thereby, confirming that NORs in A. gigas are GC-rich.

The pattern of heterochromatin distribution in specimens of $A$. gigas analyzed in the present work comprised small blocks of C-bands at the pericentromeric region of most chromosomes. Marques [19] also found reduced heterochromatic blocks, weakly stained at the centromeric region of chromosomes of A. gigas, and referred to its chromosomes as poor in heterochromatin. In both populations of $A$. gigas studied so far, the ribosomal sites at NOR-bearing chromosomes lacked heterochromatin segments.

The application of base-specific fluorochromes allowed us to evaluate the chemical nature of distinct heterochromatic regions. Therefore, the apparently homogeneous Cbands after Giemsa staining were classified as GC- or ATrich, or else as neutral.

When C-bands were stained sequentially with fluorochrome $\mathrm{CMA}_{3}$ and DAPI, the heterochromatic blocks at pericentromeric regions of three chromosomes were $\mathrm{CMA}_{3}$ positive and DAPI positive, since they must carry both GCand AT-rich segments (Fig. 3b and c). Cytogenetic analyses in Harttia loricariformis [24] also revealed chromosomal regions positive to either $\mathrm{CMA}_{3}$ or DAPI staining. According to these authors, the presence of neutral chromosomal regions should be regarded as a rare feature in fish. On the other hand, other chromosomes presented only $\mathrm{DAPI}^{+} \mathrm{C}$ bands, demonstrating they are AT-rich. As previously com-


Fig. (3). Sequential staining of C-bands in Arapaima gigas: a) Giemsa staining; b) $\mathrm{CMA}_{3}$ staining; and c) DAPI staining. The black arrows indicate the secondary constriction; the white arrows indicate the neutral bands, the arrows with $\left(^{*}\right)$ indicate the GC-rich bands; and the arrowheads indicate only the AT-rich bands. Bar $=5 \mu \mathrm{m}$. 
mented, the GC-rich segments $\left(\mathrm{CMA}_{3}{ }^{+}\right)$were restricted to NORs (Fig. 3b).

Based on RAPD data, Marques [19] showed a remarkable genetic homogeneity among individuals of A. gigas from Araguaya River, which might suggests the occurrence of a single population within the sampled area. Moreover, microsatellite and mtDNA studies in specimens collected at seven distinct sites in the Amazon basin revealed a high gene flow among localities, indicating that A. gigas composes a single connected population, where the gene flow becomes restricted only over long distances, higher than $2500 \mathrm{~km}$ [7].

Although there is little cytogenetic information about $A$. gigas, the available data support a karyotypic constancy of this species. This is reinforced by molecular studies carried out other distinct population [19]. Such conserved genetic and cytogenetic patterns are detected throughout the Amazon territory, and probably, climate features should constrain the distribution of this species. Our data corroborate previous studies in $A$. gigas and allow a better understanding about the population dynamics of a potentially threatened species.

\section{ACKNOWLEDGEMENTS}

We would like to thank Coordenação de Aperfeiçoamento de Pessoal de Nível Superior (CAPES) and Universidade Estadual de Londrina for the financial support. The collection of specimens was licensed by IBAMA (Instituto Brasileiro do Meio Ambiente e dos Recursos Naturais Renováveis).

\section{REFERENCES}

[1] Nelson JS. Fishes of the world. $4^{\text {th }}$ ed. New Jersey: John Wiley \& Sons 2006.

[2] Ferraris Jr CJ. Family Arapaimatidae. In: Reis RE, Kullander SO, Ferraris Jr CJ, Eds. Check list of the freshwater fishes of south and central america. Porto Alegre: Edipucrs 2003.

[3] Santos GM, Ferreira EJ, Zuanon JAS. Peixes comerciais de Manaus. Manaus: IBAMA/AM, ProVárzea; 2006.

[4] Lundberg JG, Chernoff B. A Miocene fossil of the Amazonian fish Arapaima gigas (Teleostei, Arapaimidae) from the Magdalena river region of Colombia - Biogeographic and evolutionary implications. Biotropica 1992; 24: 2-14.

[5] Farias I P, Hrbek T, Brinkmann $\mathrm{H}$, et al. Characterization and isolation of DNA microsatellite primerss for Arapaima gigas, an economically important but severely over-exploited fish species of the Amazon basin. Mol Ecol Notes 2003; 3: 128-30.
[6] Hrbek T, Farias IP, Crossa M, et al. Population genetic analysis of Arapaima gigas, one of the largest freshwater fishes of the Amazon basin: implications for its conservation. Anim Conserv 2005; 8: 297-308.

[7] Hrbek T, Crossa M, Farias IP. Conservation strategies for Arapaima gigas (Schinz, 1822) and the Amazonian várzea ecosystem. Braz J Biol 2007; 4: 909-17.

[8] Marques DK, Venere PC, Galetti PM Jr. Chromosomal characterization of the bonytongue Arapaima gigas (Osteoglossiforme: Arapaimidae). Neotrop Ichthyol 2006; 4: 215-18.

[9] Fenocchio AS, Bertollo LAC. A simple method for fresh-water fish lymphocyte culture. Rev Bras Genet 1988: 11; 847-52.

[10] Reeves A, Tear J. MicroMeasure for Windows, version 3.3. 2000. Free program distributed by the authors over the Internet. Available from: http://www.colostate.edu/Depts/Biology/MicroMeasure

[11] Levan A, Fredga K, Sandberg AA. Nomenclature for centromeric position on chromosomes. Hereditas 1964; 52: 201-20.

[12] Howell WM, Black DA. Controled silver staining of nucleous organizer regions with a protective colloidal developer: a 1-step method. Experientia 1980; 36: 10014-15.

[13] Heslop-Harrison JS, Schwarzacher T, Anamthawat-Jonsson K, et al. In situ hybridization with automated chromosome denaturation. Technique 1991; 3: 106-9.

[14] Cuadrado A, Jouve N. Mapping and organization of highlyrepeated DNA sequences by means of simultaneous and sequential FISH and C-banding in 6x-Triticale. Chromosome Res 1994; 2: 231-338.

[15] Gerlach WL, Bedbrook JR. Cloning characterization of ribosomal RNA genes from wheat and barley. Nucleic Acids Res 1979; 7 : 1869-85.

[16] Schweizer D. Simultaneous fluorescent staining of R bands and specific heterochromatic regions (DA-DAPI bands) in human chromosomes. Cytogenet Cell Genet 1980; 27: 190-93.

[17] Sumner AT. A simple techinique for demonstrating centromeric heterochromatin. Exp Cell Res 1972; 75: 304-6.

[18] Goulding M, Barthem R, Ferreira EJG. The Smithsonian atlas of the Amazon. Washington: Smithsonian Institution Press 2003.

[19] Marques DKS. Caracterização genética do pirarucu Arapaima gigas (Cuvier) (Teleostei, Osteoglossidae) da bacia TocantinsAraguaia, Estado do Mato Grosso. PhD Thesis. Universidade Federal de São Carlos, São Carlos-SP 2003.

[20] Navarrete MC, Júlio Jr. H. Cytogenetic Analysis of four Curimatids from the Paraguay basin, Brazil (Pisces: Characiformes: Curimatidae). Cytolgia 1997; 62: 241-7.

[21] Moreira-Filho O, Bertollo LAC, Galetti Jr PM. Struture and variability of nucleolar organizer regions in Parodontidae fish. Can J Genet Cytol 1984; 26: 564-8.

[22] Rosa R, Bellafronte E, Moreira-Filho O, Margarido VP. Constitutive heterochromatin, $5 \mathrm{~S}$ and $18 \mathrm{~S}$ rDNA genes in Apareiodon sp. (Characiformes, Parodontidae) with a ZZ/ZW sex chromosome system. Genetica 2006; 128: 159-66.

[23] Margarido VP, Galetti Jr PM. Heterochromatin patterns and karyotype relationships within and between the genera Brycon and Salminus (Pisces, Characidae). Genet Mol Biol 1999; 22: 357-61.

[24] Kavalco KF, Pazza R, Bertollo LAC, et al. Heterochromatin characterization of four fish species of the family Loricariidae (Siluriformes). Hereditas 2004; 141: 237-42

(C) Rosa et al.; Licensee Bentham Open.

This is an open access article licensed under the terms of the Creative Commons Attribution Non-Commercial License (http://creativecommons.org/licenses/by$\mathrm{nc} / 3.0 /$ ), which permits unrestricted, non-commercial use, distribution and reproduction in any medium, provided the work is properly cited. 